\title{
CHRONIC HALOPERIDOL TREATMENT INCREASED CALCIUM-DEPENDENT PHOSPHORYLATION IN RAT STRIATUM
}

\section{Yuen-Sum Lau and Margaret E. Gnegy}

Department of Pharmacology, Creighton University Medical School Omaha, NE 68178 and University of Michigan Medical School, Ann Arbor, MI 48109

(Recelved in final form November 5, 1981)

\section{Summary}

In previous studies, we observed that when rats were chronically treated with haloperidol, there was a significant increase of calmodulin activity in their striatal membranes. Calmodulin is known to modulate calcium-dependent protein phosphorylation in neural membranes. In the present study, we found that the total ${ }^{32} \mathrm{P}$-incorporation in the striatal proteins from chronic haloperidol-treated rats was significantly increased in comparison to saline-treated rats. A majority of the phosphorylation was attributed to the calcium-mediated activity, since it could be blocked by a calcium chelating agent (EGTA). By using EGTA to inhibit phosphorylation, the results indicated that the haloperidol-treated rats had approximately 3.5-fold greater $\mathrm{Ca}^{++}-$dependent protein kinase activity than the saline-treated rats. Exogenous calcium alone was insufficient to stimulate phosphorylation in the haloperidol-treated rats to the same magnitude as in the saline-treated rats. Calmodulin may be required. 32 -incorporation of two striatal proteins at molecular weight 40 and 52 kilodaltons were markedly stimulated by calcium. Cyclic AMP-mediated phosphorylation seemed to take only a small part in the alteration of total phosphorylation. Therefore, the increase of calmodulin activity and calcium-dependent phosphorylation appears to play a major role in the drug-induced dopamine receptor supersensitivity in rat striatum.

A number of neurological syndromes (e.g. tardive dyskinesia) are developed as a consequence of chronic treatment with neuroleptic drugs. In rats chronically treated with haloperidol, a dopamine receptor antagonist, there is an increase of stereotypic behavior after challenges with dopaminergic receptor agonists (1). This alteration of behavioral manifestation has been associated with the increase of dopamine receptor binding sites (2) and the elevation of dopamine-sensitive adenylate cyclase activity (3) in the striatum. Most recently, we have also observed an increase of calmodulin (a calcium-binding protein) activity in the chronic haloperidol-treated rat striatal membranes (4). In the present study, we examined the effects of this chronic haloperidol treatment on calcium-mediated protein phosphorylation in rat striatal particulate preparations.

\section{Methods}

Animal treatment and striatal particulate preparation. Male, Sprague Dawley rats $(120-150 \mathrm{~g})$ were injected subcutaneously daily for 20 days with 
either saline $(0.2 \mathrm{ml})$ or haloperidol $(1 \mathrm{mg} / \mathrm{kg})$. Five days after the termination of treatment, the animals were sacrificed by decapitation. Striata from each animal were isolated and immediately homogenized in 9 volumes of ice-cold $50 \mathrm{mM}$ Piperazine-N, $\mathrm{N}^{\prime}$-bis [2-ethane-sulfonic acid] (PIPES) buffer, pH 7.0 , containing $10 \mathrm{mM} \mathrm{MgCl} 2$. The homogenate was centrifuged at $27,000 \mathrm{~g}$ for 20 minutes at $4^{\circ} \mathrm{C}$. The pellet was washed once and then resuspended in the same buffer for the use in phosphorylation assays. For determining calcium-dependent phosphorylation, $1.2 \mathrm{mM}$ ethylene glycol bis-( $\beta$-aminoethyl ether) $-\mathrm{N}, \mathrm{N}^{\prime}$-tetraacetic acid (EGTA) was included in the homogenizing and resuspending medium.

Protein phosphorylation assays. Calcium-dependent protein phosphorylation in the striatal preparations from saline- or haloperidol-treated rats was measured in an assay medium ( $0.1 \mathrm{ml}$ final volume) containing 50 mM PIPES buffer, $\mathrm{pH} 7.0,10 \mathrm{mM} \mathrm{MgCl} 2,0.1 \mathrm{mM}$ dithiothreitol, $25 \mu \mathrm{M}$ ATP (1 $\mathrm{MCi}^{32} \mathrm{P}-\mathrm{ATP}$ per assay) and $20 \mu l$ of the striatal sample protein which was suspended in $1.2 \mathrm{mM}$ EGTA. Hence the final concentration of EGTA in each assay was $0.24 \mathrm{mM}$. Protein content of each sample was determined by the method of Lowry, et al. (5). An equivalent amount of protein $(80 \mu \mathrm{g})$ from the striatum of the control and the drug-treated rats was used in each assay to initiate the reaction. The reactions were carried out at $30^{\circ} \mathrm{C}$ and terminated by pipetting 25 ul of the sample on to a Whatman 3MM filter disc which was washed immediately with ice-cold $10 \%$ trichloroacetic acid 3 times at 15 minute intervals. The filter was finally washed once with $95 \%$ ethanol, once with ether and then air-dried before the ${ }^{32} \mathrm{P}$-incorporated activity was counted by using liquid scintillation detection.

Phosphoprotein analysis. Since total ${ }^{32} \mathrm{P}$-incorporation as determined by TCA precipitation method may also include its incorporation into phospholipids and acyl-phosphate bonds in the particulates, protein phosphorylation was also analyzed by using sodium dodecyl sulfate (SDS)-polyacrylamide gel electrophoresis (6) and autoradiography. The phosphorylation assay was carried out similarly as described above, except that the reactjon was terminated by adding $25 \mathrm{Hl}$ of SDS-stop solution (2\% SDS/62.5 mM Tris-HCl, pH $6.8 / 10 \%$ glycerol/5\% 2-mercaptoethanol/0.001\% bromophenol blue) into the sample. The sample was boiled for 3 minutes before it was applied to a $5-15 \%$ SDS-polyacrylamide gradient gel. Six proteins with known molecular weights (phosphorylase b, bovine serum albumin, ovalbumin, carbonic anhydrase, soybean trypsin inhibitor and a-lactalbumin) were used as standards. After electrophoresis, the gel was stained, destained and dried accordingly (6). Autoradiography of the gel was performed by overlaying the gel with a Kodak $x-$ ray film $(X R-5)$ in the dark for 70 hours. Phosphorylated protein bands were also qualitatively scanned by using a densitometer (E-C Apparatus Corp.).

Rat striatal particulate preparation contains high concentrations of calcium and calmodulin (7). In order to quantitate the $\mathrm{Ca}^{++}$effect on protein phosphorylation in this preparation, a Ca++-EGTA buffer was used. The free calcium concentrations reported in this study were calculated according to Nanninga and Kempen ( 8 ) where the concentrations of EGTA, Mg, ATP and the buffer $\mathrm{pH}$ were taken into consideration. All data were calculated in terms of mean \pm S.E.M. Statistical analysis was performed by using the $t$ test for group comparison. A $\mathrm{P}<0.05$ was considered significant.

\section{Results}

Time course of protein phosphorylation. Initial experiments were performed to determine the time of incubation required for optimal 
${ }^{32} \mathrm{P}$-incorporation in the rat striatal particulate preparation. A time dependent $32 \mathrm{P}$-incorporation with a peak response at 2 minutes of incubation was observed in this preparation (FIG. 1). This incubation period (2 min) was therefore chosen to examine and compare the protein phosphorylation in salineand haloperidol-treated rats. A large component of protein phosphorylation in this preparation can be inhibited by pretreating the samples with a calcium chelating agent, EGTA ( $0.1 \mathrm{mM}$ and $0.24 \mathrm{mM}$ final assay concentration) (FIG. 1). Therefore, this component represents the calcium-dependent phosphorylation since its activation requires the presence of calcium.

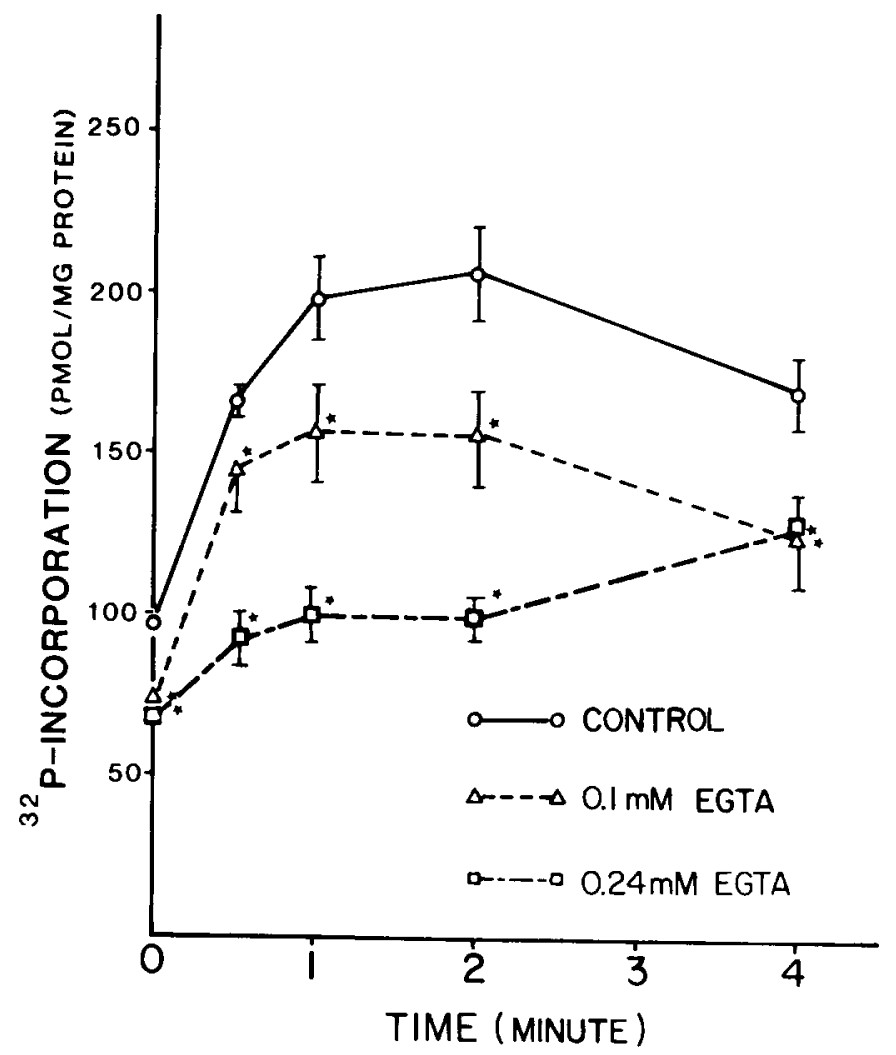

FIG. 1

Time course of $32 \mathrm{P}$-incorporation in rat striatal particulate preparation. $\mathrm{N}=5$. $32 \mathrm{P}$-incorporation was time-dependent and an optimal incorporation was obtained after 2 minutes incubation. *A significant amount of 32 -incorporation was inhibited when the preparation was pretreated with EGTA.

Effect of chronic haloperidol treatment on calcium-dependent phosphorylation. The total phosphorylation (without EGTA pretreatment) in the striatal proteins from five of the six haloperidol-treated rats was 
significantly higher than the six saline-treated rats (TABLE I). When striatal particulates were prepared in the presence of $1.2 \mathrm{mM}$ EGTA, phosphorylation in both saline- and haloperidol-treated rats was markedly inhibited (TABLE I). These results were analyzed by using a ratio of calcium-dependent phosphorylation (Total - in presence of EGTA) versus the calcium-independent phosphorylation (in presence of EGTA). These ratios revealed that the $\mathrm{Ca}^{++}$-dependent phosphorylation activity in the haloperidol-treated rats was about 3.5-fold greater than that in the saline-treated rats (TABLE I).

\section{TABLE I}

Calcium-Dependent Protein Phosphorylation in the Striatum of Chronically Treated Rats

\begin{tabular}{lccc}
\hline Treatment & Total & EGTA & $\begin{array}{c}\text { Ca }{ }^{++} \text {Dependent } \\
\text { Activity Ratio } \\
\text { (TOTAL-EGTA) }\end{array}$ \\
\hline & pmol/mg protein/2 min \pm S.E.M. & \\
Saline $(\mathrm{N}=6)$ & $290 \pm 20$ & $100 \pm 16$ & 1.9 \\
Haloperidol $(\mathrm{N}=5)$ & $370 \pm 21^{\mathrm{b}}$ & $46 \pm 10^{\mathrm{b}}$ & $7.0^{\mathrm{b}}$ \\
\hline
\end{tabular}

a The striatum was pretreated with $1.2 \mathrm{mM}$ EGTA. The final concentration of EGTA in the assay was $0.24 \mathrm{mM}$. Time of incubation was 2 minutes.

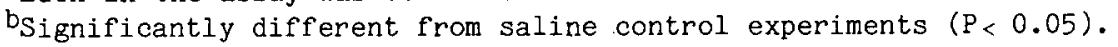

In the EGTA pretreated particulate preparations, protein phosphorylation in both saline- and haloperidol-treated rats could be stimulated by the exogenously added calcium in a concentration-dependent manner (FIG. 2 ). It should be noted, however, that protein phosphorylation in the haloperidol-treated rats could not be stimulated by calcium alone to the same level as in the case of saline-treated rats (FIG. 2).

Comparable observations were also obtained when these experiments were analyzed by using SDS-polyacrylamide gel electrophoresis and autoradiography (FIG. 3). Similarly, EGTA inhibited phosphorylation in the particulate preparation from haloperidol-treated rats more effectively than in those from saline-treated rats. Phosphorylation was stimulated proportionally by $0.15 \mathrm{mM}$ and $0.25 \mathrm{mM}$ calcium $\left(1.4 \times 10^{-7} \mathrm{M}\right.$ and $1.1 \times 10^{-5} \mathrm{M}^{-1}$ ree Ca ${ }^{++}$respectively) in both groups of the animals. It is noteworthy that two particular phosphoproteins at molecular weight of approximately 40 and 52 kilodaltons were markedly stimulated by calcium in comparison to other phosphoproteins (FIG. 3).

Effect of chronic haloperidol treatment on cyclic AMP-dependent phosphorylation. Cyclic AMP-dependent phosphorylation was measured in the same manner as in the calcium mediated experiments. $1 \mathrm{mM}$ theophylline was included in the assay. $5 \mu \mathrm{M}$ exogenously added cyclic AMP did not further increase 32P-incorporation in EGTA treated particulate preparations from both salineand haloperidol-treated rats (TABLE II). However, the endogenous cyclic AMP level in the haloperidol treated rats, when expressed by the protein kinase activity ratio (- cyclic AMP/+ 5uM cyclic AMP) as suggested by Corbin et al. (9) on lysine-rich histone f2 (250 $\mathrm{kg}$ ) phosphorylation, was significantly higher than in the saline-treated rats (TABLE II). 


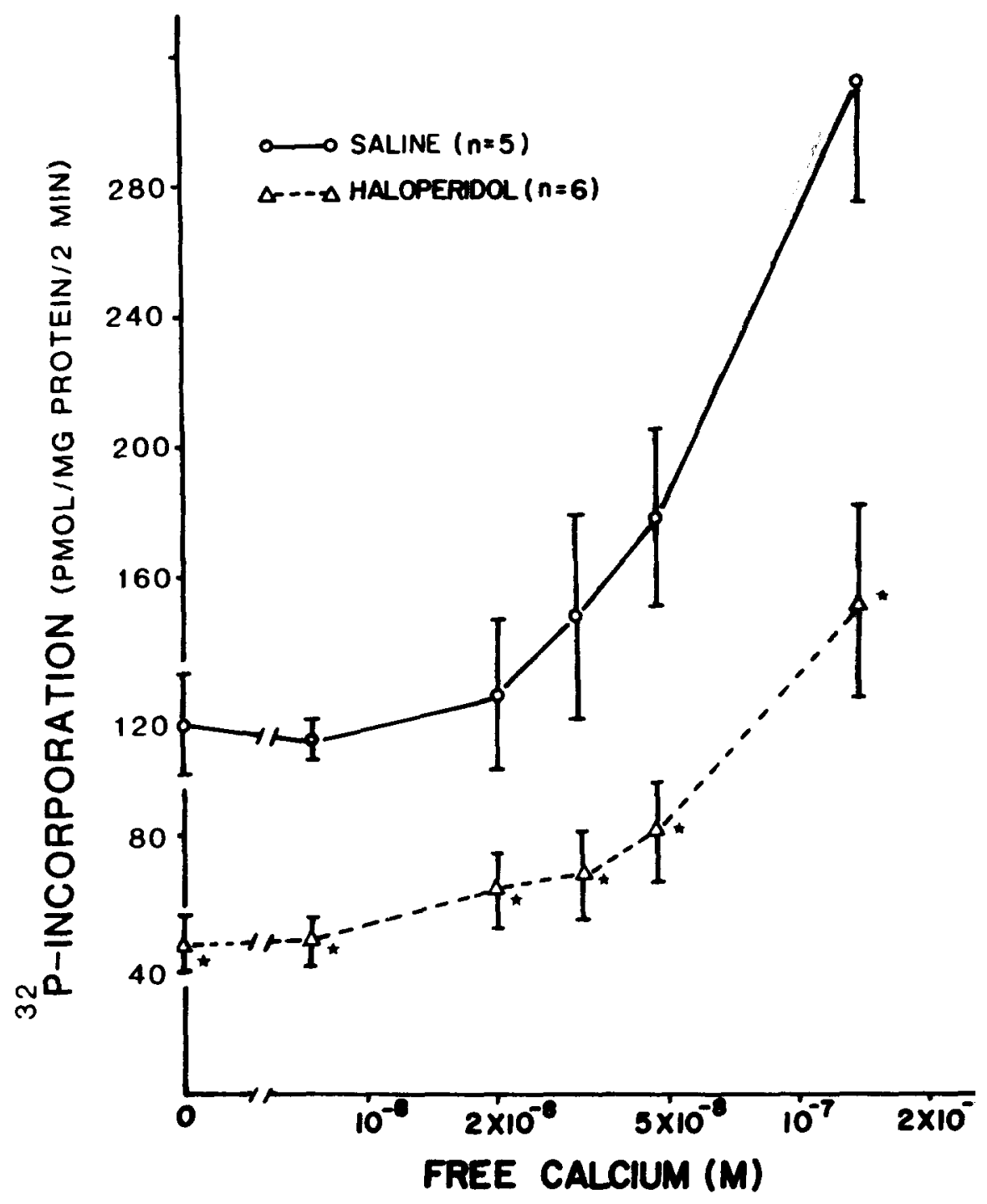

FIG. 2

Dose-response study of calcium on protein phosphorylation in rat striatal particulate preparations after chronic treatment with saline or haloperidol. The striatal particulate preparations were pretreated with $1.2 \mathrm{mM}$ EGTA ( $0.24 \mathrm{mM}$ assay concentration). Abscissa: calculated free calcium concentration (see Methods). Calcium at increasing concentrations stimulated $32 \mathrm{P}$-incorporation in preparations from both saline- and haloperidol-treated rats. Calcium alone, however, did not restore the phosphorylation in the preparations from haloperidol-treated rats to the same level is in the saline-treated rats. 


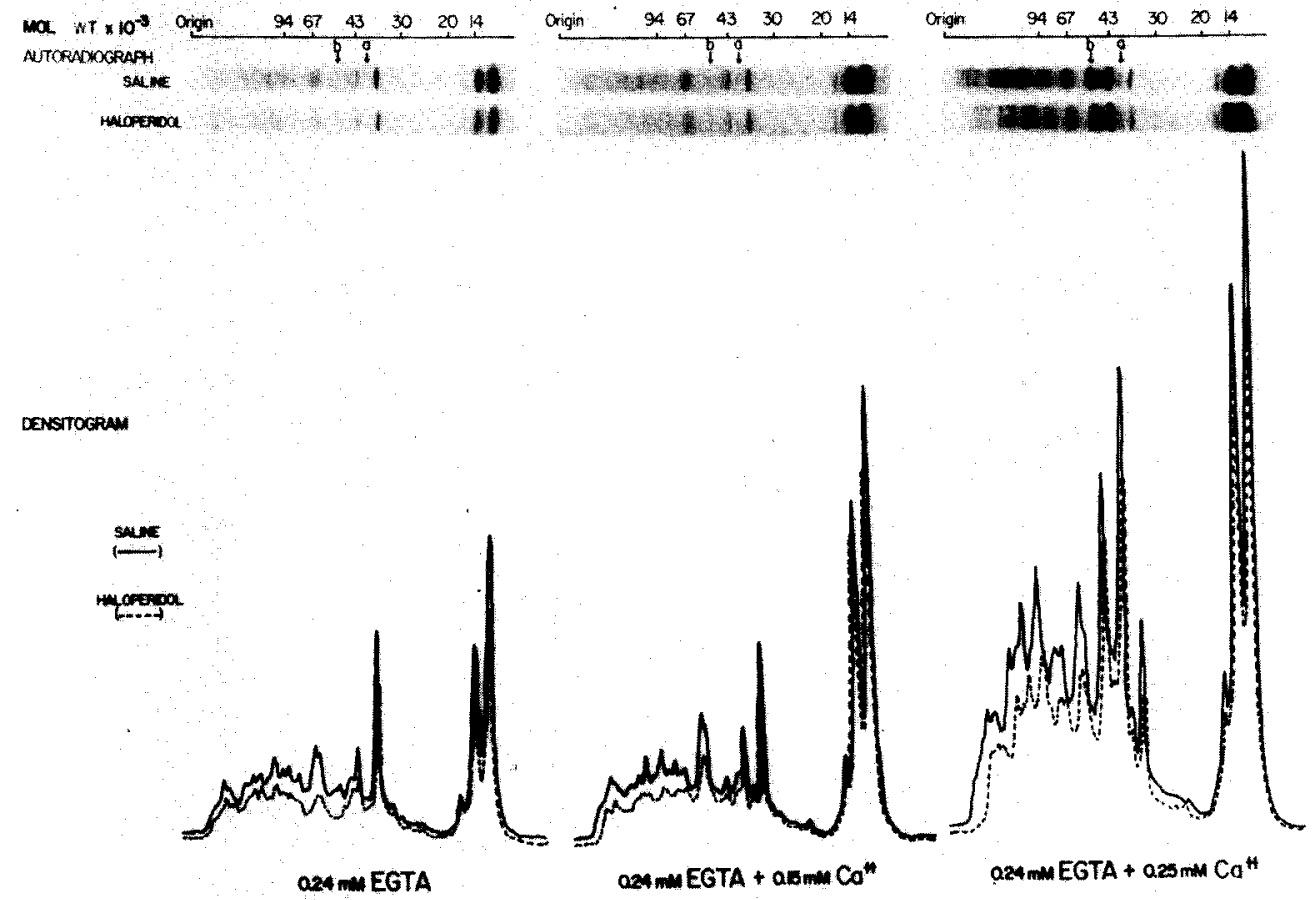

FIG. 3

Effect of chronic saline and haloperidol treatments on calcium dependent phosphorylation in rat striatal particulate preparations. Autoradiograph and densitogram. A representative result from six experiments. Two phosphoproteins ( $a$, b at M.W. 40 and 52 kilodaltons respectively) were markedly stimulated by calcium. For other details, see Results and Legend for FIG. 2.

\section{Discussion}

Dopamine receptor supersensitivity and intensified stereotypic behavior are generally observed after the chronic administration of neuroleptic drugs (10). The drug-induced up-regulation of the dopamine receptor responses has been correlated with corresponding increases in various pharmacological and neurochemical parameters in the striatum, such as the dopamine receptor binding sites (2), dopamine-sensitive adenylate cyclase activity (3) and calcium-calmodulin activity (4). In this study, we further demonstrated that there is a significant increase of striatal calcium-dependent protein phosphorylation in rats chronically treated with haloperidol. Thus, the calcium chelating agent (EGTA) inhibited protein phosphorylation more effectively in the haloperidol-treated rats than in the saline-treated rats. 
TABLE II

Effect of Cyclic AMP $(5 \mu M)$ on Phosphorylation in the Striatum of Chronically Treated Rats

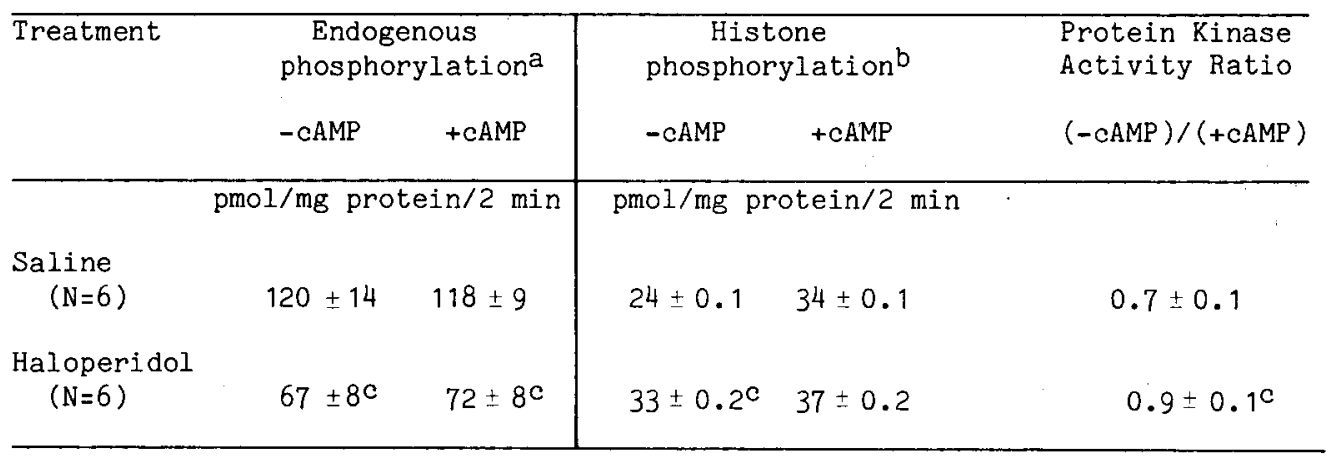

aphosphorylation was studied by using endogenous substrate in the absence or presence of $5 \mu \mathrm{M}$ cyclic AMP. $1.2 \mathrm{mM}$ EGTA-treated particulate preparations were used. $5 \mu \mathrm{M}$ added cyclic AMP did not affect phosphorylation.

bPhosphorylation was performed by using $250 \mu \mathrm{g}$ histone f2 as substrate for $1.2 \mathrm{mM}$ EGTA treated preparations. The values were corrected for endogenous phosphorylation.

Significantly different from the value for saline-treated rats $(P<0.05)$.

When calcium was restored in the preparations, a calcium concentration dependent phosphorylation could be obtained in both groups of animals. It should be emphasized, nevertheless, that exogenously added calcium alone was not sufficient to activate the phosphorylation in particulate preparations from haloperidol-treated rats to the same level as seen in the saline-treated rats. We have previously reported that haloperidol-treated rats contain a small but significant increase (28\%) of striatal membrane calmodulin activity (4). We have also observed that when the striatal particulate preparation was pretreated with EGTA $(1.2 \mathrm{mM})$, this procedure substantially removed the endogenous calcium ions and calmodulin (7). Therefore, the greater inhibition of calcium-dependent phosphorylation by EGTA in the haloperidol-treated rats as shown in this report is expected, due to the reason that EGTA treatment would abolish a greater amount of calmodulin activity in the haloperidol-treated rats than in the saline-treated rats. Preliminary experiments have indicated that addition of authentic calmodulin in the phosphorylation assays potentiated the $\mathrm{Ca}^{++}$-dependent phosphorylation in the haloperidol-treated rats to the same magnitude as in the saline-treated rats (Lau, unpublished data).

Calcium and calmodulin have been proposed to play an intimate role in neurotransmission through the regulation of neuronal protein phosphorylation (11). The results from this study have demonstrated a positive association between $\mathrm{Ca}^{++}$-dependent protein phosphorylation and dopamine receptor supersensitivity. Furthermore, we also identified that two striatal proteins at molecular weight of 40 and 52 kilodaltons are highly phosphorylated in the presence of calcium in comparison to other phosphoproteins as revealed by the SDS-polyacrylamide gel electrophoresis and autoradiography experiments. These proteins may be important in modulating dopamine receptor sensitivity. 
The total $32 \mathrm{P}$-incorporation in the haloperidol-treated rats was significantly higher than in the saline-treated rats. This observation could be largely attributed to the elevation of the calcium-kinase activity (as discussed above). The possibility remains, however, that the increase of phosphorylation in the chronic haloperidol treated rats may also be resulted from a decrease of phosphoprotein phosphatase activity in these animals. The activity of this enzyme was not determined in this study. An additional explanation for our observations could be due to the activation of adenylate cyclase activity (3) and thus the increase of endogenous cyclic AMP levels (as represented by the increase of cyclic AMP-dependent protein kinase activitJ ratio), although the former (calcium) effect was much more pronounced than the latter (cyclic AMP) effect. The state of phosphorylation after chronic saline or haloperidol treatment was not affected by exogenously added cyclic AMP. The reason for the lack of cyclic AMP-stimulation on phosphorylation by using erdogenous protein kinase and substrate in this study is not known. It is possible that the endogenous substrate for cyclic AMP-dependent protein kinase in this preparation is quite different in nature than the histone substrate. The possible relationship between the increased calcium-dependent phosphorylation and the elevated cyclic AMP content in the chronic haloperidol-treated rats requires further investigation.

\section{Acknowledgments}

The authors thank Ms. C. Stratford and Dr. T. Ueda for advice and providing facilities for autoradiographic work; Dr. F. Dowd for providing lysine-rich histone $\mathrm{f} 2$ and valuable discussion during the preparation of this manuscript; Ms. L. Johnson and Ms. M. Markytan for typing the manuscript; McNeil Laboratories for the generous supply of haloperidol. This work was supported in part by a NSF grant BNS 78-06964 (MEG) and BRSG RR05390 from NIH to Creighton University (YSL). Preliminary results of this study were presented at the FASEB meetings, Atlanta, GA, April 12-17, 1981.

\section{References}

1. A.C. SAYERS, H.R. BURKI, W. RUCH and H. ASPER, Psychopharmacol. (Berl.) 41:97-104 (1975).

2. D.R. BURT, I. CREESE and S.H. SNYDER, Science 196:326-328 (1977).

3. M. GNEGY, P. uZUNOV and E. COSTA, J. Pharmacol. Exp. Ther. 202:558-564 (1977).

4. M. GNEGY and Y.S. LAU, Neuropharmacol. 19:319-323 (1980).

๖. O.H. LOWRY, N.J. ROSEBROUGH, A.L. FARR and R.J. RANDALL, J. Biol. Chem. 193:265-275 (1951).

6. U.K. LAEMMLI, Nature 227:680-685 (1970).

7. Y.S. LAU and M.E. GNEGY, J. Pharmacol. Exp. Ther. 215:28-34 (1980).

8. L.B. NANNINGA and R. KEMPEN, Biochem. 10:2449-2456 (1971).

9. J.D. CORBIN, T.R. SODERLING and C.R. PARK, J. Biol. Chem. 248: 1813-1821 (1973).

10. H.L. KLAWANS, JR., Am. J. Psychiatry 130:82-86 (1973).

11. P: GREENGARD, Fed. Proc. 38:2208-2217 (1979). 